\title{
Research on New Compressed Air Energy Storage Technology*
}

\author{
Xian $\mathrm{Ma}^{1}$, Jingtian $\mathrm{Bi}^{1}$, Weili Chen ${ }^{1}$, Zhisen $\mathrm{Li}^{2}$, Tong Jiang ${ }^{1}$ \\ ${ }^{1}$ State Key Laboratory of Alternate Electrical Power, System with Renewable Energy Sources, \\ North China Electric Power University, Beijing, China \\ ${ }^{2}$ Tai'an Power Supply Company, Shandong Electric Power Corporation \\ Email: maxiansdu1989@163.com
}

Received January, 2013

\begin{abstract}
In recent years, wind power generation and photovoltaic power generation have been developing rapidly, and the installed capacity of the new resources generation has been keeping a fast growth every year. But with the incorporation into the grid, the new resources generation that has the properties such as randomness and volatility causes certain risks to the power grid, which results in the falling of the incorporation proportion instead of rising. This paper describes the current status and development problems of the new energy in China, and gives a brief introduction of characteristics of various energy storage technologies. This paper focuses on the analysis of the compressed air energy storage technology in recent years and new developments and the latest technology at home and abroad, additionally, the paper introduces a new concept of the compressed air energy storage system.
\end{abstract}

Keywords: New Energy; Wind Power; Power Storage Technology; Compressed Air Energy Storage

\section{Introduction}

UN Secretary-General Ban Ki-moon, the "Sustainable Energy for All” initiative was launched in late 2011, specified the year of 2012 as "Sustainable Energy for All” International Year. In the period of fast development of new energy, China, the United States, Germany, Japan and many other countries are all striving to fight for the exploitations of new energy to stimulate the future economy growth, so the development and utilization of new energy, energy-saving technologies and energysaving products have become the key points of the national energy strategy for every country.

Coal, oil, natural gas and other fossil fuels will eventually dried up, coupled with the needs of environmental protection, so that large-scale application of renewable energy is imperative. The renewable energy such as wind power and solar energy have the properties as randomness and volatility, and frequent wind power off-gird pose a threat to the safe operation of the power grid, the above situations result in increasing proportion of abandoned wind yearly[1]. The combination of Energy storage technologies and renewable energy generation technology not only can improve the stability of the system and improve power quality, but also improve resource

\footnotetext{
"Supported by the National High Technology Research and Development of China 863 Program (2012AA050208).
}

utilization. Therefore, the large-scale use of renewable energy need the support of large-scale and distributed energy storage technology.

\section{Analysis of Energy Storage Technology}

\subsection{Premise of Energy Storage Technology}

According to statistics released by the National Grid, at the end of June 2012, China's grid-connected wind power has reached 52.58 million kilowatts and overtaken the U.S. to become the world's biggest wind power country. But at the same time the year of 2011 as a turning point in the development of wind power industry in China entered a period of steady development instead of rapid growth. In the year of 2011, the china's wind turbines in operation were suspended for 19 hours every day, the amount of 100 billion $\mathrm{kWh}$ of wind power was abandoned and the percentage of abandoned wind power was over $12 \%$, which is the equivalent of 330 million tons of standard coal consumption, or 10 million tons of carbon dioxide emissions to the atmosphere. The loss was more than 50 billion that is accounting for nearly $50 \%$ of the wind power industry profitability.

If the new energy generation plants such as wind power and solar photovoltaic power plants were equipped with energy storage devices, firstly, the energy storage components would adjust the output of the unit and solve the 
randomness and uncontrollable problems of the new energy power generation itself to reduce the impact of the output variation of the new energy on the grid, secondly, the devices would store the electrical energy during the period of abundant electricity and release the electricity when it is necessary. The combination of energy storage with large capacity wind power generation system is an important part of the renewable energy, especially for wind power plants.

Figure 1 represents the development of wind power in China from 2008 to 2012. It is not difficult to find that the cumulative installed capacity of wind power grows fast, but the wind turbines grid ratio shows a downward trend.

\subsection{Introduction of Energy Storage Technology}

Existing electrical energy storage technologies include pumped storage, compressed air energy storage, flywheel energy storage, battery energy storage, superconducting magnetic energy, super capacitor energy storage and so on [2].

- The flywheel energy storage system absorbs electrical power from grid and transfers it into mechanical energy during a low load period and the fast rotating flywheel functions as prime motor to drag the generators run when the load need is tedious [3]. Flywheel system has the advantage that no friction loss, wind resistance, long life and no environmental impact. The disadvantage is that the relatively low the energy density is relatively low and the cost of system security is high, so this technology doesn't show the priority in small system and it now mainly works as assistant for the battery system.

- The superconducting magnetic energy storage system transfers the grid power to magnetic field energy directly, which doesn't need the energy exchange [4]. This storage system is characterized by simple techniques, timeproof equipment, high density, fast response speed, low loss and costliness. This system is not adapted by distributed power systems until now.

- $\quad$ Super capacitor is mainly used for load smoothing and power quality high peak power occasions for a short time in the power system and have not been widely used because of the expensive price [5].

- Battery energy storage system is a chemical power storage system and the batteries need to maintain a certain temperature in the work process. Proportion of the cost for insulation takes a big part in existing battery energy storage power station and when the temperature reaches a certain limit, there will be a certain security risk [6].

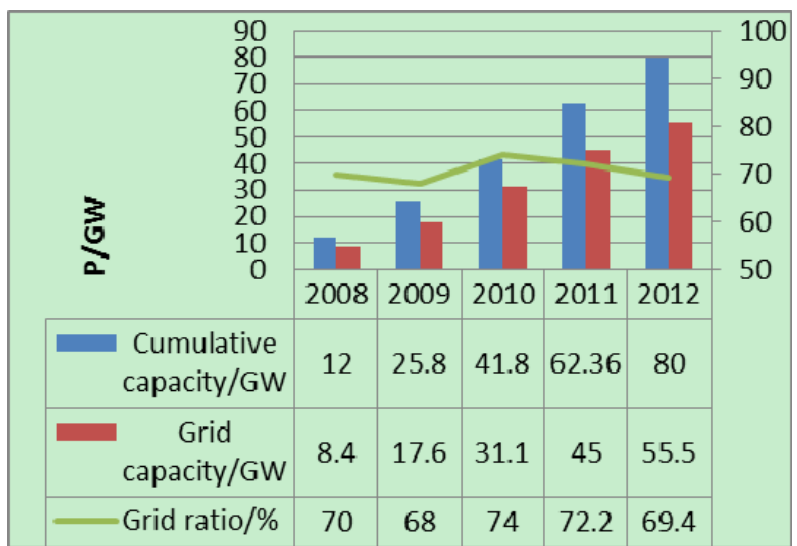

Figure 1. China's wind power development in the 2008-2012.

- $\quad$ The pumped storage power plant is flexible to start and stop and able to improve and stabilize the system voltage. But it requires special geographical conditions for the construction of reservoirs and dams, and the construction period is long, the initial investment is huge, and the large area of vegetation will be submerged and even cities, which will lead to ecological and immigration issues.

\section{Compressed Air Energy Storage, CAES}

Compressed air energy storage is second to pumped storage in the large-capacity storage technology. Although pumped storage technology has been developed widely, but because of its own constraints, there is a growing hope is attached to compressed air energy storage technology in large-capacity storage technology [7].

Compressed air energy storage technology made many breakthroughs in the decade's years from the traditional hot generation technology using gas turbine to the cool generation technology transferring the gas potential energy of the compressed air to other forms of energy, and the concept of compressed air energy storage is not limited to using gas turbine. The following content will analyze both characteristics and latest technical development of hot generation and cool generation of compressed air energy storage.

\subsection{Hot Generation Compressed Air Energy Storage}

Hot generation compressed air energy storage is referred to traditional technology, which is actually gas turbine power plant for peaking regulation. It uses power energy to press the air into the underground gas chamber and store the energy, and releases the high-pressure air that burning with combustible gas for generation. Compared with other energy storage technologies, hot generation 
CAES has advantages such as large capacity, long working hours, good economic performance and long life of charge-discharge cycle and so on. But it has disadvantages, for example, hot generation CAES must still rely on burning fossil fuels to provide heat with the usage of gas turbine, which is unable to reduce carbon emissions and doesn't meet the requirements of the development of green renewable energy.

\subsection{Cool Generation Compressed Air Energy Storage}

The innovative concept of cool generation CAES was proposed in the past one or two years, which achieve the exchange between the gas potential energy and other forms of energy. Such a storage system does not need to burn the combustible gas, so it will reduce carbon emissions to achieve the goal of the green energy storage.

March 2012, CAES Technology Company Sustain X obtained the patent of constant-temperature CAES system. The patent technology is like: During the highpressure air expansion, its temperature tends to fall according to the ideal gas law, and then the spray mechanism will release the spray at a suitable high temperature to make the temperature in the vessel remain at a constant level, so the spray transfers thermal energy to the gas. During air compression, its temperature tends to rise, and then the spray mechanism will release the spray at a suitable low temperature to make the temperature in the vessel remain at a constant level, so the gas will transfer thermal energy to the spray and the hot water can also be used for other forms of acting [8]. Figure 2 is patent schematic diagram of Sustain X Company. Although in theory, the efficiency of the constant temperature CAES system is better than that of conventional systems, the director Mark Johnson of Advanced Research Projects Agency of the U.S. Department of Energy project thought that it may need five years or longer to prove its economy and find a wide range of applications.

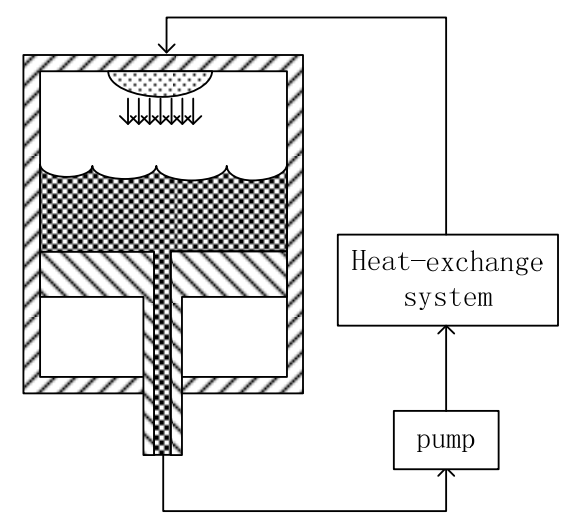

Figure 2. Diagram of thermostat compressed air system of Sustain $\mathrm{X}$.
In early 2013, Sustain X Company also announced a U.S. patent, which will collect waste heat for generation to save the leak energy that was taken away by steam. Dax Kepshire, Sustain X company vice president, said that if the system was equipped to a conventional power plant, which will act as a peak-regulation plant and will be cheaper than gas peak-regulation plant.

Sustain X Company uses ground air tank to replace the cave, which diminish the problem of geographical restrictions, and it uses the piston instead of the turbines for generation in order to reduce the size and cost of the gas tank.

In addition to Sustain X Company, Danielle A - Fong, the co-founder of Light Sail Energy Company, founded a compressed air energy storage technology, which is still based on CAES, but the difference is that the technique uses the piston divides the cylinders into two parts. The piston will move during the high-pressure gas expansion or the gas compression and drives piston rod, which will achieve the exchange between the gas potential energy and mechanical energy [9]. Figure 3 is patent schematic diagram of Light Sail Energy Company. While the existing difficulty is that the temperature will reach $1000^{\circ} \mathrm{C}$ when the air is compressed, this means a large part of loss of energy by the way of heat. She invents a technique that the hot water is separated away in the process of the air compression compressed air and uses the thermal energy through the circulation loop to minimize the loss [10]. Danielle believes that her approach would cost only $1 / 10$ compared with the same power of the battery storage.

Although China's CAES technology researches and projects are still focused to the use of the gas turbine power generation, the concept of combination between compressed air energy storage and pumped storage is proposed, and the patent of water-gas encompassing vessel energy storage system is one example. During air expansion, the compressed air stored in the vessel is not used to combust in a gas turbine, but rather the air push the water flows from the vessel to the low-pressure pool

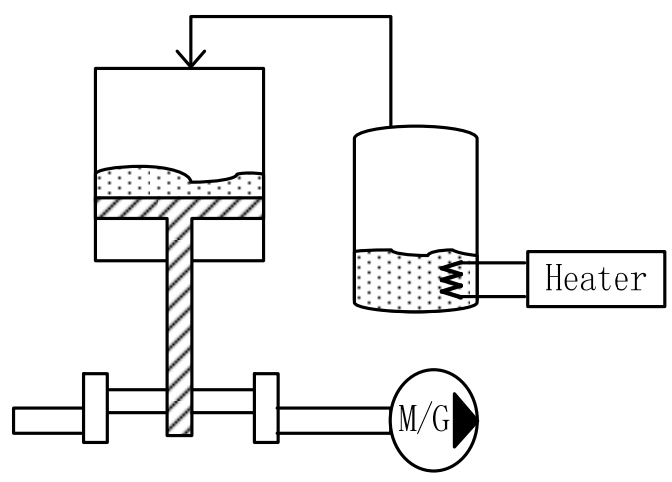

Figure 3. Diagram of Danielle A • Fong's patent technology. 


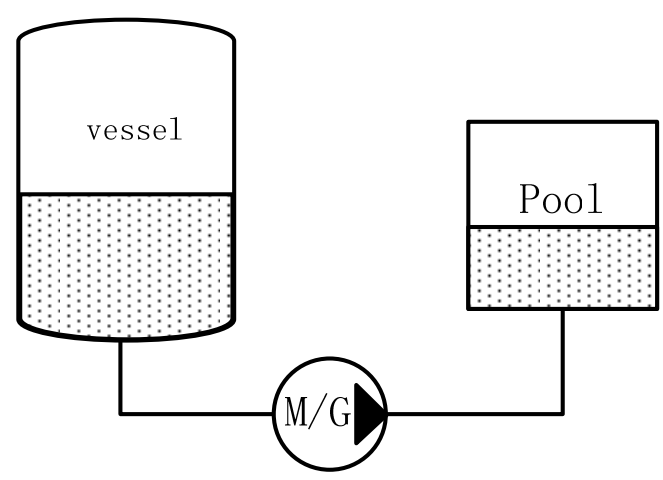

Figure 4. Diagram of patent technology of water-gas encompassing vessel energy storage system.

and drive the turbine into generation. During air compression, the air pump uses the power energy squeeze the air into the vessel, and the water pump extracts the water from low-pressure pool into the vessel [11]. Figure 4 is patent schematic diagram of water-gas encompassing vessel energy storage system. The system uses the hydroturbine for generation, which will obtain higher efficiency of energy exchange than the traditional CAES technology. But the technique has shortcoming either, for example, during the water flow promoted by the highpressure air, the gas volume increases, and the pressure gradually reduces, so the pressure forced on the hydroturbine is not constant, which will lead to low-efficiency operation of hydroturbine and off-generation beyond a certain pressure range.

The innovation of CAES technology has raised the possibility of a new green and low consumption energy storage technology; however we also need to constantly improve and perfect these technologies in order to achieve the goal of the green and economic energy storage.

\section{Conclusions}

The large-scale usage of renewable energy and grid operation needs the support of large-scale and distributed energy storage technology, and now the rapid develop- ment of various energy storage technologies also make a new turn for the new energy grid operation. The cool generation compressed air energy system technology brings a possibility for green and economic energy storage technology. The future energy storage system needs a variety of storage patterns to match up with each other.

\section{REFERENCES}

[1] U.S., "Energy Information Administration," Renewable Energy Consumption and Electricity, Preliminary Statistics, 2010,Washington, DC: U.S., Energy Information Administration, 2011.

[2] G. Rachel, “2009 Renewable Energy Data Book,Washington,” DC:US Department of Energy, 2010.

[3] C. S. Sun, Y. N. Wang and X. R. Li, "Synthesized Power and Frequency Control of Wind Power Generation," Proceedings of the CSEE, Vol. 28, No. 29, 2008, pp. 111-116.

[4] S. J. Cheng, J. Y. Wen and H. S. Sun, "The Storage Technology and Its Application in Modern Power System," Electrotechnical Journal, Vol. 24, No. 4, 2005, pp. 1-8.

[5] J. M. Geng, T. M. Li and W. Wang, "Research on the Characteristics of Energy Storage for Supercapacitor," Low Voltage Apparatus, Vol. 5, 2008, pp. 16-18.

[6] M. Ding, Y. Y. Zhang, M. Q. Mao, X. P. Liu and N .Z. Xu, "Economic Operation Optimization for Microgrids Including $\mathrm{Na} / \mathrm{S}$ Battery Storage, Proceedings of the CSEE, Vol. 31, No. 4, 2011, pp. 7-14.

[7] B. Zhou, "Development of Large Compressed Air Storage Power Generation System,” China Electrical Equipment Industry, Vol. 3, 2004, pp. 43-45.

[8] X. Sustain, Inc.High-Efficiency Liquid Heat Exchange in Compressed-gas Energy Storage Systems: US, Vol. 8, No. 171, 728B2[P/OL].2012-05-08[201-01-23].

[9] “Light Sail Energy,” Inc., Compressed Gas Storage: US, 2011/ 0204064A1[P/OL].2011-08-25[2013-01-23].

[10] “Light Sail Energy,” Inc., Compressed Air Energy Storage System Utilizing Two-phase Flow to Facilitate Exchange: US,2012/0269651A1[P/OL].2012-10-25[2013-01-23].

[11] H. R. Wang, "Water-gas Encompassing Electric Power," Energy Storage System: CN, 102434362A [P/OL]. 201205-02[2013-01-23] 